Voces de mujeres en la Edad Media 



\section{Voces de mujeres en la Edad Media}

Entre realidad y ficción

Editado por

Esther Corral Díaz 
Este volumen está financiado con cargo a una ayuda del Ministerio de Economía y Competitividad (ref. FFI2014-55628-P), en el marco del proyecto Voces de mujeres en la Edad Media: realidad y ficción, y de la Red de Estudios medievales interdisciplinares (ref. ED431D R2016/004)

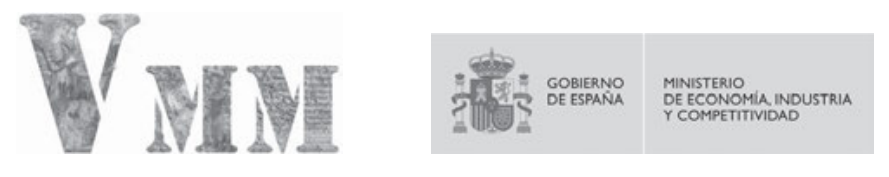

XUNTA DE GALICIA

consellería de cultura, educación E ORDENACIÓN UNIVERSITARIA

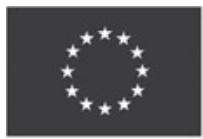

\section{Unión Europea}

Fondo Europeo

de Desarrollo Regional

"Una manera de hacer Europa"

ISBN 978-3-11-059664-9

e-ISBN (PDF) 978-3-11-059675-5

e-ISBN (EPUB) 978-3-11-059489-8

\section{(cc) BY-NC-ND}

This work is licensed under the Creative Commons Attribution-NonCommercial NoDerivatives 4.0 License. For details go to http://creativecommons.org/licens-es/by-nc-nd/4.0/.

\section{Library of Congress Control Number: 2018947015}

\section{Bibliographic information published by the Deutsche Nationalbibliothek}

The Deutsche Nationalbibliothek lists this publication in the Deutsche Nationalbibliografie; detailed bibliographic data are available in the Internet at http://dnb.dnb.de.

(C) 2018 Esther Corral Díaz, published by Walter de Gruyter GmbH, Berlin/Boston Typesetting: Integra Software Services Pvt. Ltd.

Printing and binding: $\mathrm{CPI}$ books $\mathrm{GmbH}$, Leck

Cover image: Fresco detail from the Castello della Manta (Saluzzo, Italy). ( ) FAI - Fondo Ambiente Italiano, Archivio Fotografico (photo by Fabrizio Giordano). 